\title{
Measuring the human body's micro-climate using a thermal manikin
}

\author{
Conrad Voelker ${ }^{1}$, Silvio Maempel ${ }^{2}$, Oliver Kornadt ${ }^{3}$ \\ ${ }^{1}$ University of Kaiserslautern, Department of Modeling in Building Physics, Paul-Ehrlich-Str. 29, 67663 Kaiserslautern, Germany \\ ${ }^{2}$ Ed. Züblin AG, Mies-van-der-Rohe-Straße 6, 80807 München \\ ${ }^{3}$ University of Kaiserslautern, Department of Building Physics / Low-Energy Buildings, Paul-Ehrlich-Str. 29, 67663 Kaiserslautern, Germany
}

(Received 23 September 2013; accepted 18 March 2014; published online 25 March 2014)

\section{Copyright Notice}

Copyright 2014 John Wiley \& Sons. This article may be downloaded for personal use only. Any other use requires prior permission of the author and John Wiley \& Sons.

The following article appeared in Indoor Air 24 (6), 567-579 (2014) and may be found at

https://doi.org/10.1111/ina.12112.

\section{Abstract}

The human body is surrounded by a micro-climate which results from its convective release of heat. In this study, the air temperature and flow velocity of this micro-climate were measured in a climate chamber at various room temperatures, using a thermal manikin simulating the heat release of the human being. Different techniques (Particle Streak Tracking, thermography, anemometry, and thermistors) were used for measurement and visualization. The manikin surface temperature was adjusted to the particular indoor climate based on simulations with a thermoregulation model (UCBerkeley Thermal Comfort Model). We found that generally, the micro-climate is thinner at the lower part of the torso, but expands going up. At the head, there is a relatively thick thermal layer, which results in an ascending plume above the head. However, the micro-climate shape strongly depends not only on the body segment, but also on boundary conditions: the higher the temperature difference between the surface temperature of the manikin and the air temperature, the faster the air flow in the micro-climate. Finally, convective heat transfer coefficients strongly increase with falling room temperature, while radiative heat transfer coefficients decrease. The type of body segment strongly influences the convective heat transfer coefficient, while only minimally influencing the radiative heat transfer coefficient. 


\section{Introduction}

The climate surrounding the human body has a great impact on human well-being. However, indoor climate is also influenced by the heat-release of the human body itself. Convective heat release from the human body creates a micro-climate consisting of a boundary layer surrounding the body and an ascending plume of heat above the head which both differ greatly in temperature and flow from that of the indoor climate. A comparison of all body segments shows that this micro-climate can vary greatly in thickness and shape. Murakami et al. (1997) showed that the thickness of the thermal boundary layer surrounding the feet is comparatively small $(5 \mathrm{~cm})$ but that it becomes thicker as one moves up the body. Large surfaces along the flow direction, such as the chest and back are covered by a relatively thick layer, which is associated with a low convective heat loss. The thermal layer around the neck was measured at $19 \mathrm{~cm}$. The thickness of the velocity boundary layer differs from the thermal boundary layer, which has a thickness of around $8 \mathrm{~cm}$ at the feet and about $15 \mathrm{~cm}$ at the head. The velocity of the ascending air flow reaches its maximum within the plume above the head, measuring 0.2-0.3 m/s (Murakami, 2002, Murakami et al., 1999).

Under normal conditions, the convective heat transfer of the human body is dominated by buoyancy-driven convection. One of the driving forces is the temperature difference between the surface of the human body and the surrounding air. The other primary factor is flow velocity, which is significantly responsible for convective heat release. The higher the flow velocity, the higher the heat transfer coefficient. Other parameters such as clothing or activity are secondary, as they have an influence on the surface temperature of the human body and hence on the temperature difference.

The properties of the human body's micro-climate are highly dependent on its boundary conditions and the particular body segment in question. The measurements introduced in this paper confirm this claim. Values found in earlier research provided a good estimation, but did not sufficiently describe the micro-climate around the human body. With regard to heating, ventilation and air conditioning, the micro-climate of the human body has been simulated to some extent by Gao and Niu (2004), Dygert et al. (2009), Deevy et al. (2008) and Sevilgen and Kilic (2011) using Computational Fluid Dynamics (CFD). Craven and Settles (2006) measured the human micro-climate using human volunteers and a Schlieren camera. Schlieren technique has been also used by Tang et al. (2011) to investigate human exhaled airflows for the reason of aerosol infection control. Worth mentioning is also the benchmark experiment of Nilsson et al. (2007), who used a thermal manikin in a climate chamber.

This paper features numerous new approaches. First of all, the measurements were conducted with a combination of local measurement methods (anemometry, thermistors) and global measurement methods such as thermography and Particle Streak Tracking. Altogether, four independent measurement methods were used to measure air velocity and air temperature. Additionally, the control of the surface temperature of the male manikin used in this study (most of the existing studies deal with a female body) was driven by a complex human thermoregulation model. Finally, the study also investigates the impact of different room air temperatures on the micro climate.

The findings of this paper generate a better understanding of human body's micro-climate. This knowledge is useful in fields dealing with thermal comfort, HVAC (heating, ventilation and air conditioning), indoor air quality and the spread of airborne diseases. The measurements can also be used for the validation of CFD simulations. Furthermore, a comprehensive knowledge of the micro-climate surrounding the human body is necessary to transfer data from CFD simulations to a thermal comfort model (Voelker and Kornadt, 2010, Voelker and Kornadt, 2012).

\section{Measurement setup}

\subsection{Climate chamber}

A series of measurements were carried out in a climate chamber ( $3 \mathrm{~m} \times 3 \mathrm{~m} \times 2.44 \mathrm{~m})$. The chamber is tempered using water-bearing capillary tubes placed under the plaster of every surface (4 walls, floor, and ceiling). Additionally, the chamber is equipped with a ventilation system with an adjustable air change rate and the choice between recirculated or fresh air. The ventilation as well as every single surface can be separately controlled in a temperature range of between $10^{\circ}$ and $40^{\circ} \mathrm{C}$. Hence, the climate chamber is suited for the investigation of typical indoor climates, but also for the study of phenomena such as the micro-climate surrounding the human body. All measurements in the climate chamber were performed in a steady state, which was ensured by an appropriate lead-time and constant monitoring of the indoor climate parameters. In the study, the climate chamber was equally tempered by all six surfaces while the ventilation system was switched off. The result was a relatively uniform climate with almost no vertical gradient. The air temperature was slightly above that of the walls, due to the heat released from a thermal manikin.

The chamber was also equipped with a thermal manikin (nicknamed "Feelix"). With heating wires directly under his surface, Feelix is able to simulate the skin temperature and sensible heat release of the human body. The manikin was used because the human body affects the temperature and flow conditions as a source of heat as well as an obstacle to the free flow of air (Melikov, 2004). The use of a manikin allows the investigation of the impact of the indoor climate on the human being and vice-versa. The use of artificial pump-controlled breathing within the manikin was 
not used during the measurements to avoid the transient characteristics of inhalation and exhalation.

The manikin was positioned in a sitting posture, with the outstretched arms representing a working position at a desk. To guarantee stability, the manikin was seated on a chair, but to minimize the impact on airflow, the back-rest and seat of the chair were removed. This setup is comparable to that used in other studies, and thus allows for comparison between them. Because the remaining structure of the chair had minimal contact with the manikin, the influence of heat conduction could be also ignored. Through various control modes, either the surface temperature, or the heat flux, or a "comfort mode" could be simulated. The latter is often used in the literature and is based on the simple estimation

$$
q=\frac{\theta_{\text {core }}-\theta_{\text {skin }}}{R}
$$

with a default core temperature of $36.4^{\circ} \mathrm{C}$ and a thermal resistance of $\mathrm{R}=0.054 \mathrm{~m}^{2} \mathrm{~K} / \mathrm{W}$. Instead of using this "comfort mode", the surface temperature of every single body segment was determined by the UC Berkeley Thermal Comfort Model (Huizenga et al., 2001). Similarly to the model described by Tanabe et al. (2002), this thermoregulation model segments the human body into 16 parts. In addition, every segment is divided into four concentric layers (core, muscle, fat, skin) plus and additional node for heat and moisture transfer through clothing (Voelker et al., 2009). The results are more realistic than the estimation based on equation (1) and can be easily transmitted from the model to the thermal manikin because of its similar segmentation.

Using the UC Berkeley Thermal Comfort Model, the surface temperature $\theta_{\text {skin }}$ was determined separately for each of the chosen boundary conditions (Figure $1 \&$ Table 1 in the supporting information). Based on this simulation, the surface temperature of the thermal manikin was adjusted. To simulate human thermoregulation, an activity level of 1 metabolic equivalent (1 met) was selected. The simulation was carried out until a steady state was reached, usually after $\mathrm{t}=2 \mathrm{~h}$. As the measurements were conducted with a nude manikin, clothing was neglected in the simulation (0 clo). As clothing influences the manikin's surface in terms of parameters like temperature, emissivity, surface area or surface texture, the measurements are not directly comparable to clothed humans.

\subsection{Particle Streak Tracking}

In order to detect the speed of the air flow, the twodimensional method called Particle Streak Tracking (PST) was used (Dahms et al., 2007). The whole system has been developed by the Technische Universität Berlin and can be bought from the spin-off Human Comfort Measurements $\mathrm{GmbH}$. In contrast to anemometry, the advantage of this method is the ability to measure and visualize the flow velocity in a plane. In addition, the measuring equipment causes only minimal disturbance to the flow. To help visualize

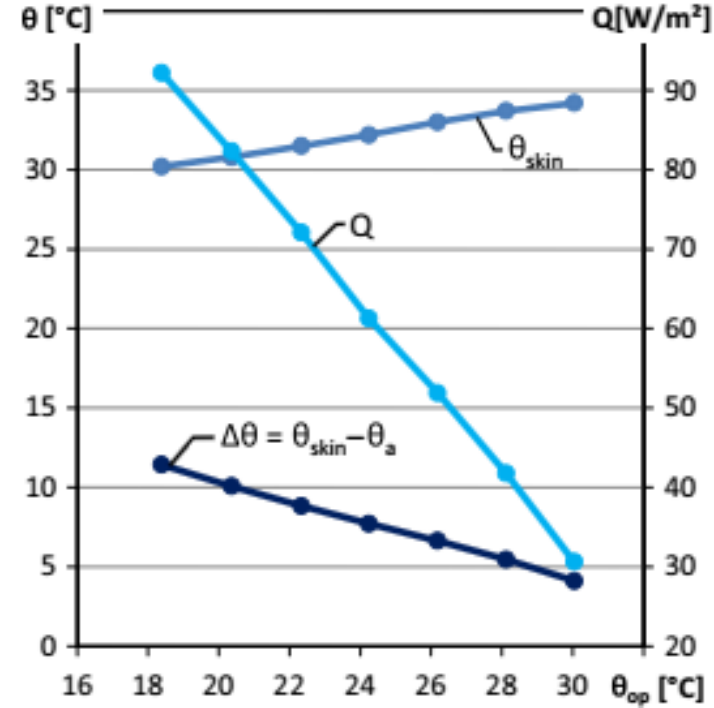

Fig. 1. Skin temperature $\theta_{\text {skin }}$ and heat loss $Q$ of the thermal manikin depending on the operative room temperature $\theta_{o p}$ (calculated by averaging air and mean radiant temperature)

the flow, a special generator injects about 200 bubbles per second into the climate chamber, each bubble about $3 \mathrm{~mm}$ across. To compensate for the mass of the bubble skin, the particles are filled with a helium mixture, which makes them essentially equal in weight to the air and produces good tracking behavior. The kinetic energy of the particle-feeding air flow is kept low by four specially made diffusers, which were arranged on both sides of the measurement field. The flow field is uniformly illuminated in a plane by light-emitting diodes (LED, see also Figure 2). These LEDs were arranged in order to make the measuring field as bright as possible and to minimize the depth of the plane $\left(d_{\max }=5 \mathrm{~cm}\right)$. In order to reduce light scattering and reflection, the background area was covered black (visible at wall and ceiling in Figure 3).

During the measurements, the light was pulsed (long pulse $2 \Delta t$, short break $\Delta t$, short pulse $\Delta t$ ), resulting in characteristic patterns made by the tracer particle, which were recorded with a high resolution camera. Because of its full frame sensor, its high resolution (21.1 megapixels) and its frame rate ( $3.9 \mathrm{fps})$, this camera is capable of documenting air-flow by tracking the movement of the relatively small and sometimes fast-moving particles.

Equipped with a lens appropriate for extremely low light intensities with a focal length of $24 \mathrm{~mm}$, the camera captured an area in the climate chamber of about $0.7 \times 1 \mathrm{~m}$ (distance to the measurement plane $d=78 \mathrm{~cm}$ ). In order to obtain meaningful, high-contrast images, the shutter time of the camera had to be adjusted to the pulse time. After preliminary investigations, an aperture of 2.5 at a sensitivity of ISO 100 , with pulse durations of $\Delta t=15 ; 18 ; 20 \mathrm{~ms}$ for single (- -) or double double pulses (- - - ) was selected.

The obtained data were then filtered in order to sharpen the contours of the particles and to suppress the measurement noise. In a following step, the generated images were superimposed onto one another, so that a mask could be created in which no particle traces were contained. From this 
mask, the individual images could be subtracted, leaving only the traces of the particles visible without a background. After entering the tolerances (length, thickness, radius, size, etc.), the particle velocity was finally calculated based on the distance between the centers of the traces and the pulse time.

To increase the density of the measured values, up to 180 images per measurement were superimposed upon one another. Subsequently, the generated vectors were compared with the original recordings. If necessary, for example, a direction was obviously incorrectly allocated, the vectors were manually removed. The number of rejected vectors correlated with the length of the pulse duration. At shorter pulse durations, not more than $10 \%$ of the vectors had to be removed. This percentage increased with longer pulse durations.

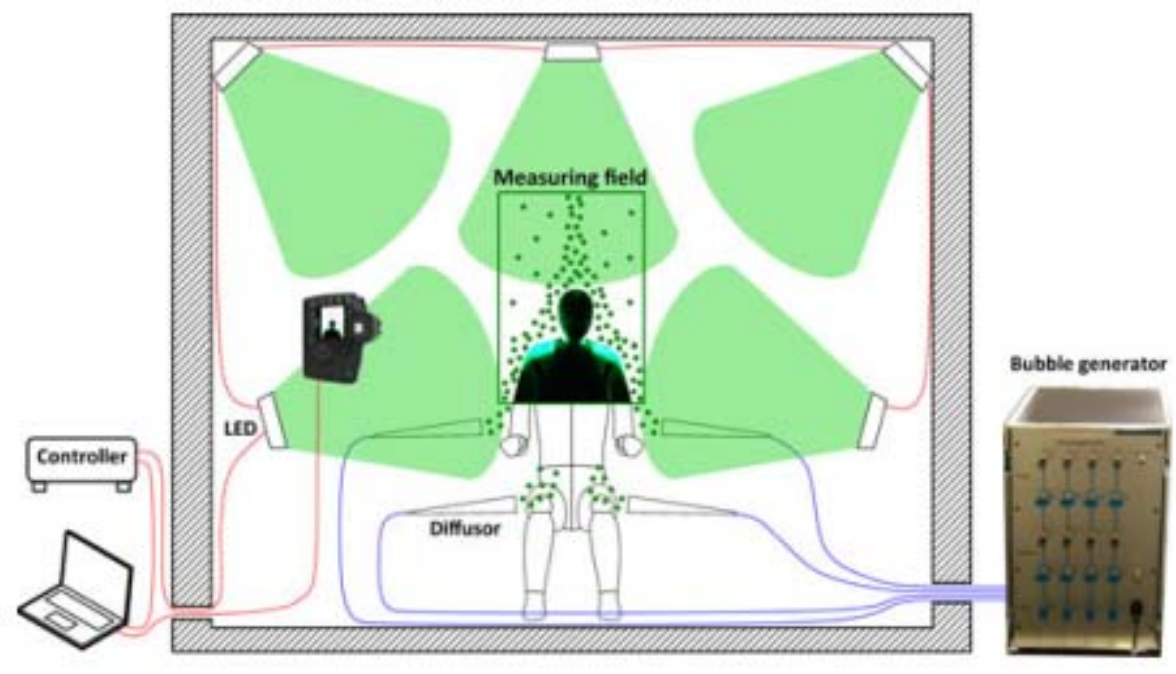

Fig. 2. Particle streak tracking: an LED illuminates particles generated by a bubble generator; a controller pulses the LED, while a high-resolution camera records.

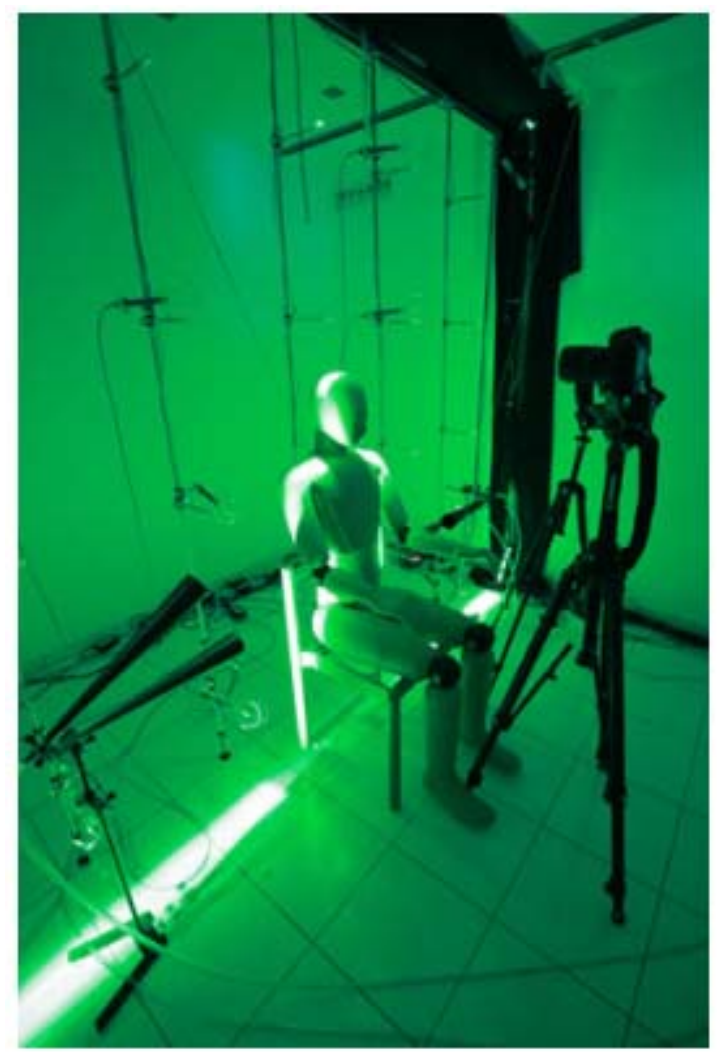

Fig. 3. Climate chamber with thermal manikin. Visible are also the diffusers of the particle streak tracking and the flow field illuminated by LEDs. In the background, several temperature and air velocity sensors are installed.
To present the flow field vectors in an equidistant grid, the results were transformed with the help of the following interpolation algorithm:

$$
v_{a}(x)=\frac{\sum_{i=1}^{n} \frac{1}{\left(x-x_{i}\right)^{2}} \cdot v_{a, i}}{\sum_{i=1}^{n} \frac{1}{\left(x-x_{i}\right)^{2}}} \text { (Müller, 2000). }
$$

A lattice spacing of $\mathrm{d}=1 \mathrm{~cm}$ was chosen. The superimposing and interpolation averages the PST measured values in terms of space and time. With this standardization it is possible to compare the PST measurements with the results of anemometry. Additionally, the data become comparable with CFD simulations which are usually based on the Reynolds Averaged Navier Stokes (RANS) equations which statistically average the fluctuations into a steady flow.

When measuring the air flow using PST, different measurement uncertainties need to be taken into account. Among others, this includes measurement errors due to the perspective, reduced trace lengths when the particles enter or leave the light while recording, curved particle paths especially resulting from turbulence, particle acceleration, and lacking tracking behavior of the particles (Müller, 2000). Due to these uncertainties, a reliable error estimation of the PST method is nearly impossible. 


\subsection{Thermography}

To visualize the temperature profile of the human body's micro climate, infrared thermography was used. Because thermography detects only surface temperatures, but not air temperature, an auxiliary work plane made of cardboard was built around the thermal manikin (Figure 4). This allowed us to visualize the corona-shaped boundary layer of the thermal manikin and allowed the temperature to be measured throughout the whole plane, not only at the individual points where the thermistors were located.

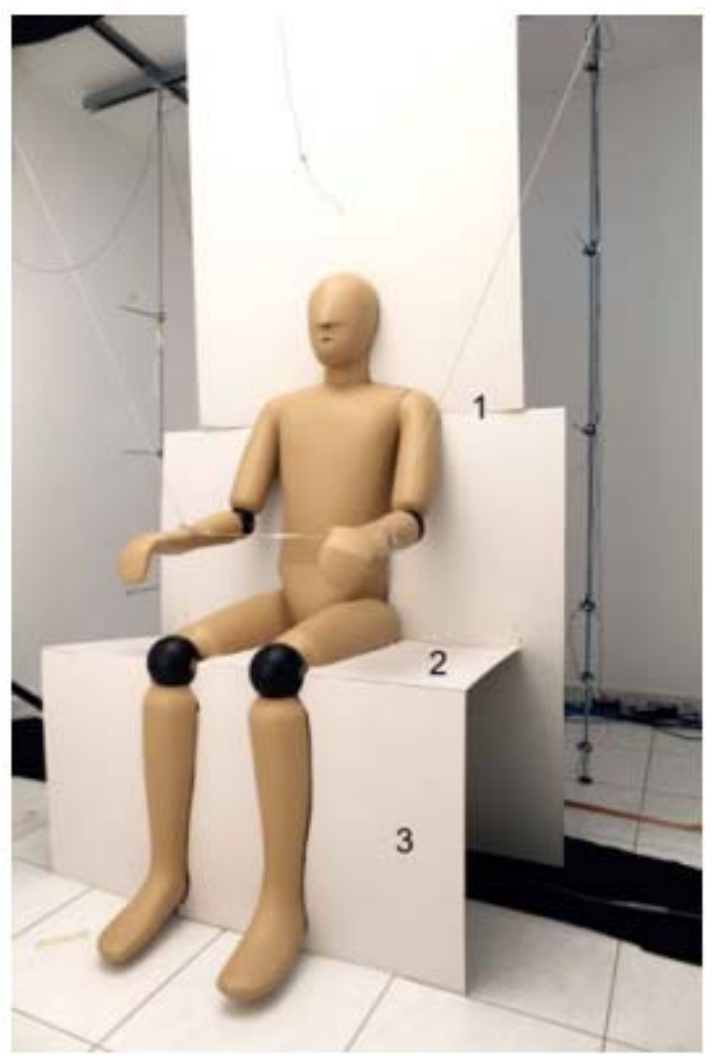

Fig. 4. Work plane made of cardboard surrounding the thermal manikin

In preliminary experiments, two different materials were tested. The first was a commercially available mosquito net made of polyester. The goal was to use the porosity of the net to keep interferences to flow conditions as low as possible. However, it was found that the surface temperature of the wall behind had an enormous influence on the thermography measurement due to the mesh size of the mosquito net. This side effect could not be eliminated, even with several layers of netting. In order to exclude this effect, further studies were performed with corrugated cardboard. According to Cehlin et al. (2002), the influence of such impervious planes on flow and temperature conditions is negligible, assuming that they are aligned parallel to the direction of air flow at low flow velocities. The measurements showed that both requirements were met.

When choosing a material for the auxiliary work plane, it is important to pay attention to its emission coefficient. On the camera-facing side of the cardboard, a compromise is necessary: on the one hand, an emission as high as possible is desirable to reduce the effects of reflective surrounding surfaces during the recording. On the other hand, a low emission reduces the influence of the radiative heat exchange with the surrounding surfaces in the period leading up to the recording. This allows the auxiliary work plane to achieve the temperature of the air undisturbed by other influences. The cardboard used is a smooth, white surface with an emissivity of $\varepsilon=0.9$.

In order to limit the influence of radiation on the side of the cardboard facing away from the camera, a reflective coating (e.g. aluminum foil) can be applied to the cardboard to increase the emission coefficient. However, during the series of measurements we carried out, this was not necessary, as the $3 \mathrm{~mm}$ thick double wave cardboard provided a good thermal insulation between front and back. Furthermore, effects of heat conduction perpendicular to the board could be regarded as rather low, since the boundary conditions were similar on both sides.

During the experiment, it was necessary to wait until the system had reached the thermal steady state, where the surface temperature of the auxiliary work plane is the same as the air temperature. This state could be reached quickly because the thin cardboard has a very low heat capacity. Yet another advantage of the cardboard used was its physical stability, allowing it to be installed so that it didn't create any obstacles to flow. A total of four planes were constructed (see also Figure 4): (1) from the hips to the ceiling in the plane of the measuring sensors, (2) a horizontal plane extending out from the mid-line of the thigh, (3) a vertical plane extending out from the mid-line of the lower leg, and (4) a vertical plane perpendicular to the first plane (not illustrated). As the horizontal cardboard at the thigh (2) might disturb the upward flow, this plane was only installed when making separate measurements. When the cardboard planes were mounted, care was taken to avoid direct contact with the surface of the thermal manikin in order to reduce heat conduction effects orthogonal to the manikin.

The camera (a Jenoptik Varioscan 3021ST with a Stirling cooler) has a resolution of $\pm 0.03 \mathrm{~K}$, so that temperature gradients can be represented quite accurately in a single thermogram. The previously discussed effects of radiation from the surrounding surfaces on the thermographic recording of the auxiliary work plane cannot be explicitly quantified because they are highly dependent on the climatic boundary conditions as well as the way they are interpreted by the user. For this reason, and similarly to PST, this method is appropriate for the visualization of quantitative data. To control the thermography measurements, a temperature sensor was mounted onto the board surface.

\subsection{Anemometry and thermistors}

To double-check the measurements of the air velocity with the PST, additional hot-wire anemometers with an accuracy of $\pm 1.5 \%$ of the measured value were used (Fig. 5). 
During the recordings, statistical fluctuations of the air velocity could be measured. The thermal manikin is not the reason for these instabilities, as it is monitored with a frequency of $40 \mathrm{~Hz}$.

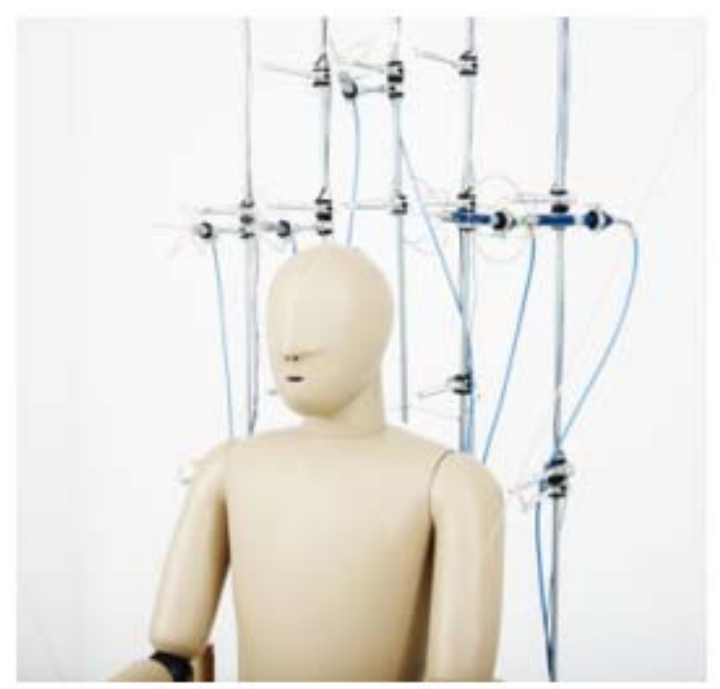

Fig. 5. Temperature and air velocity sensors surrounding the thermal manikin.

Neither is it the fault of the regulation of the climate chamber, which is more likely to be responsible for longer fluctuations. Therefore, air flow turbulence and instability are the only possible causes of the fluctuations. Hence, the measurements with the anemometers were recorded over a time period $t=1 \mathrm{~h}$ with a sampling interval of $t=1 \mathrm{~s}$ and then averaged. This makes the anemometry measurements comparable to the results of the statistically averaged PST as well as to a CFD simulation based on RANS.

To measure the air temperature, a total of 20 Negative Temperature Coefficient Thermistors (NTC) with an accuracy of $\pm 0.1 \mathrm{~K}$ were used. In preliminary measurements it turned out that the heat emitted by the hot-wire anemometers influenced the air temperature. Therefore, the air temperature and the flow velocity were subsequently measured separately.

\section{Results and discussion}

\subsection{Air velocity}

Figure 6 shows the air velocity, as measured using PST. In this figure, the original particle tracks are already converted into vectors indicating the direction and speed of the air-flow. The high density of vectors is the result of the superimposition of many individual images ("stacking"). The even higher density on the left shoulder is probably due to very high particle emission from the nearby diffuser. The upward flow around the shape of the human body is noticeably visible. Clearly, a dead zone characterized only by small-scale turbulences, is visible directly above the head. Very close to the human body, shear stress slows the boundary layer's velocity. At the surface of the skin, the flow velocity reaches zero, and increases in velocity with increasing distance from the human body.

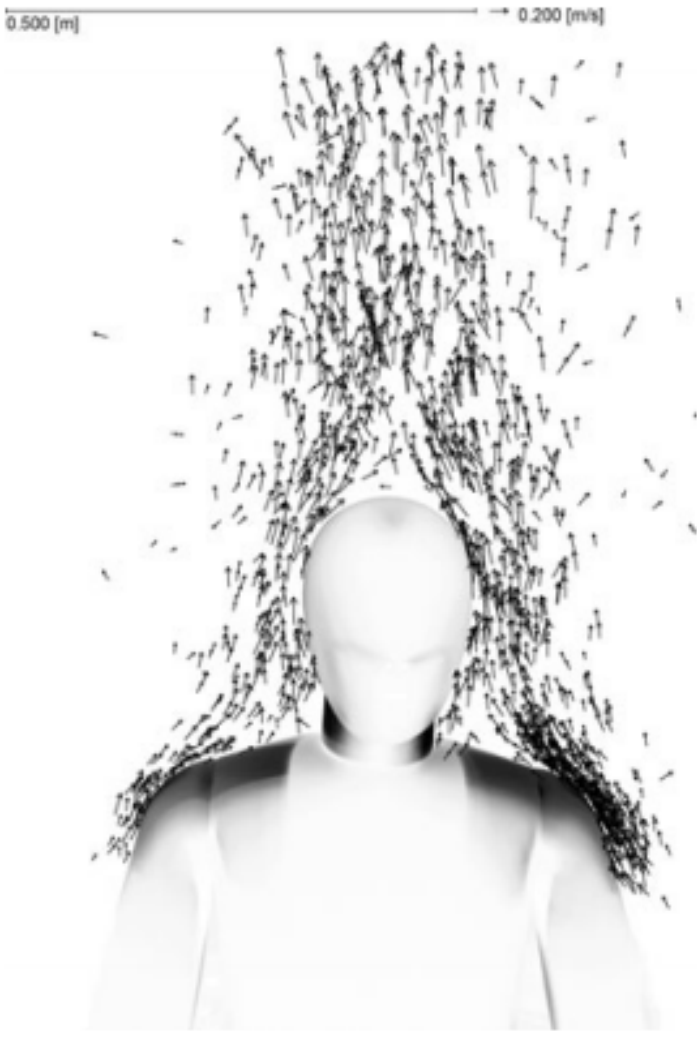

Fig. 6. Particle tracks of the upward flow of the thermal plume. The tracks are already converted into vectors indicating the direction and speed of the airflow (room temperature: $18^{\circ} \mathrm{C}$ )

As the convection is only buoyancy-driven, the velocity continues to increase, eventually reaching a maximum, and then falling back to the velocity of the undisturbed air surrounding the body. The flow separation occurs behind the thickest part of the head (supercritical flow separation), which is a result of the high Reynolds and Grashof numbers due to the turbulent flow in this region.

To transform the raw data into a standard format, the measured values were treated with an interpolation algorithm (eq. 2). In Figure 7, the interpolated results are given for the room temperatures of $18^{\circ} \mathrm{C}, 24^{\circ} \mathrm{C}$ and $30^{\circ} \mathrm{C}$. Thanks to the uniform $1 \mathrm{~cm}$ interpolation mesh, the air velocities under the different conditions are easily comparable. The flow velocity within the micro-climate is strongly dependent on the particular boundary conditions that result from the differences in temperature between the body and the surrounding air. The higher the temperature difference between surface and air temperatures, the higher the air velocity. An air temperature of $18^{\circ} \mathrm{C}$ (left figure) yields a maximum speed of slightly more than $0.3 \mathrm{~m} / \mathrm{s}$, while at $24^{\circ} \mathrm{C}$ it decreases to $0.27 \mathrm{~m} / \mathrm{s}$. At $30^{\circ} \mathrm{C}$, the air velocity is measured at only $0.2 \mathrm{~m} / \mathrm{s}$. These findings confirm the numerical simulations and measurements done by Murakami (2004).

Selected points within the micro-climate are presented in Figure 8. These are the result of the readings 

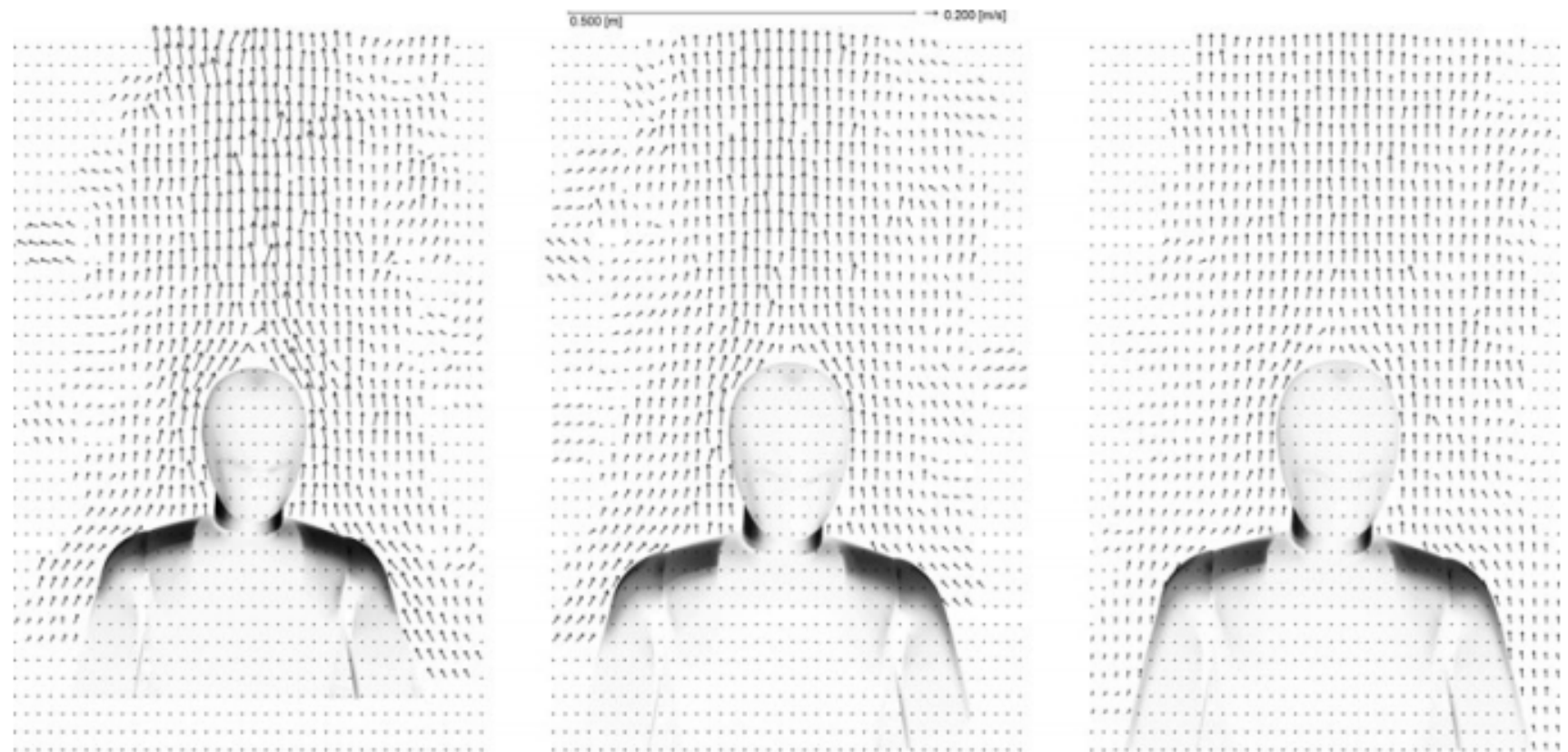

Fig. 7. Interpolated PST measurements (left: $18^{\circ} \mathrm{C}$, middle: $24^{\circ} \mathrm{C}$, right: $30^{\circ} \mathrm{C}$ ) show the influence of the room temperature on the thermal plume

from the anemometer, whose positions were shown in Figure 9. The raw data from the PST measurements are presented as a point cloud (PST). What is striking is the wide dispersion of the data, which results from the turbulence and instability of the flow. Therefore, the interpolated values - averaged in terms of time and space - are shown as a curve (PST avg). The air velocity measured by the anemometers is shown by the larger dots. The standard deviation (plotted using error bars) shows the measured fluctuations, which are particularly high directly above the manikin.

In Figures $8 \mathrm{a}-8 \mathrm{c}$, the air velocity measured along a horizontal line $6 \mathrm{~cm}$ above the head ( $141 \mathrm{~cm}$ above floor) is shown at different room temperatures. As shown above in Figure 7 , the air velocity above the human body is faster at lower room temperatures (Figure 8a) than at higher room temperatures (Figure 8c), which is a similar result to the findings of Licina et al. (2013). The reason is that the higher density gradient of the air produces more natural convection. As the error bars indicate, the standard deviation is quite high due to the instability and turbulence of the flow. Generally, the upward flow is approximately a shoulder's width wide. The influence of the dead zone directly above the head is recognizable due to lower air velocities.

Figures $8 \mathrm{~d}$ - 8f illustrate the air velocity measured along a vertical line directly above the head. In contrast to Figures $8 a-8 c$, the standard deviation of the measured flow velocity is much lower. In the area directly above the head, there are almost no particles, due to the dead zone. With increasing distance from the head, the air velocity increases. Again, the air velocity depends on the room temperature, as shown in the differences between Figures 8d and 8f. Overall, there is good agreement between the PST and the anemometry measurements.

\subsection{Air temperature}

Figure 10 shows the results of the thermography at the uniform wall temperatures of $\theta \mathrm{w}=18 ; 24^{\circ} \mathrm{C}$ and $30^{\circ} \mathrm{C}$. Each picture represents a temperature-scale of $8 \mathrm{~K}$ starting from the wall temperature. A uniform scale for all the three thermographies could not be used because if it were, no details would be visible.

Due to the heat loss of the manikin, the air temperature is slightly above the wall temperature. Due to the convective heat release of the human, the temperature of the micro-climate is always within a range between that of the undisturbed air in the room and that of the surface of the manikin. This temperature gradient is responsible for a density gradient, which is the only reason for the mass transfer in case of natural convection.

While the thermal micro-climate is very thin in the area of the lower torso, it expands as one goes upwards. The changing geometry of the body at the neck leads to a particularly pronounced expansion. In this area, the highest air temperatures are also to be found. In addition, the head is a barrier to thermal buoyancy. At the head, a relatively thick thermal layer can be found, which results in an ascending plume. This plume, which results from the ascending flow due to the heat release of the human body, has significant force. The thicknesses of the boundary layers in terms of air temperature and in terms of flow velocity are similar but not identical. The reason for the unequal thickness is the Prandtl number $\operatorname{Prair}_{2} \sim 0.7$, which is basically the ratio of the flow to 


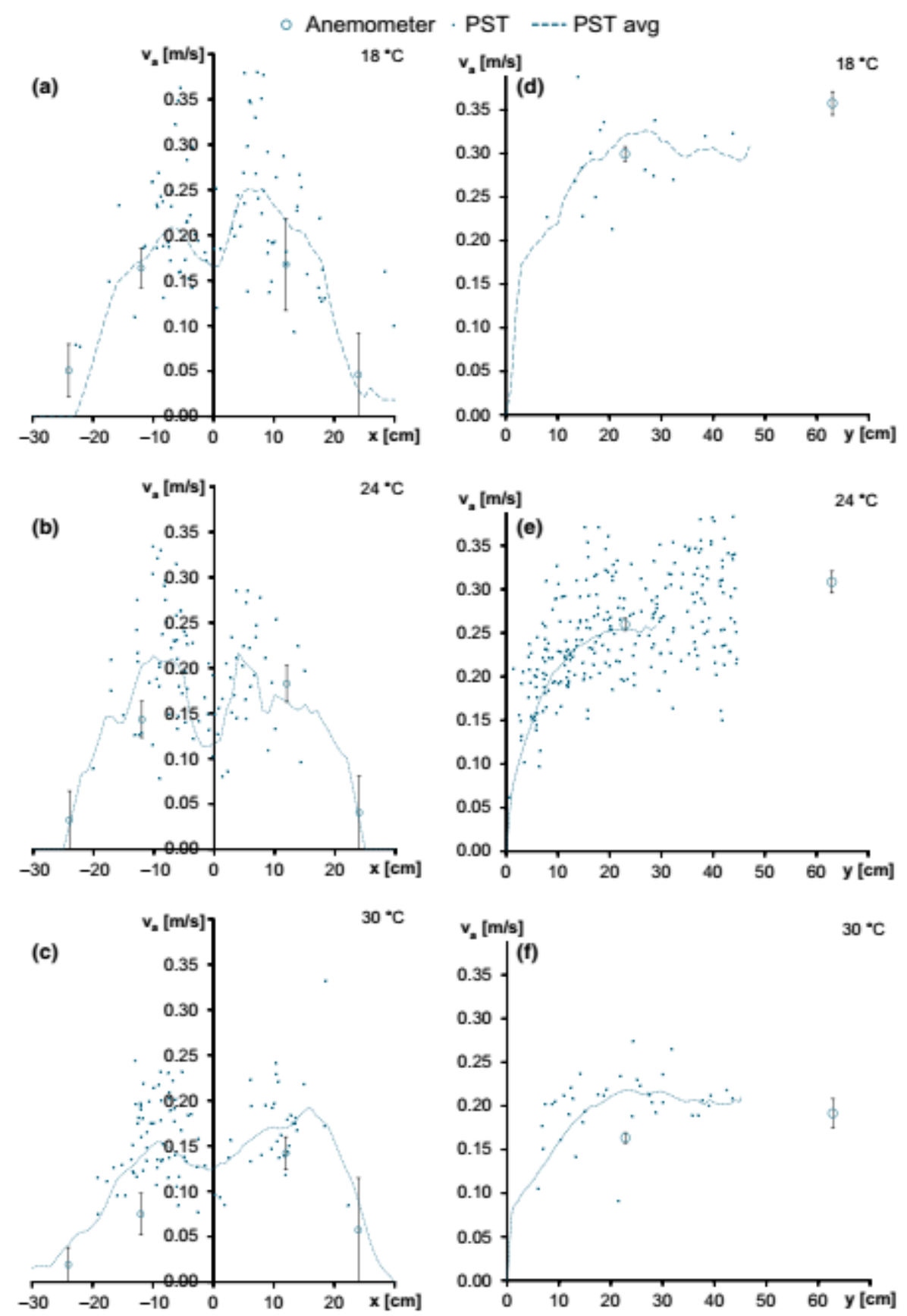

Fig. 8. Air velocity horizontally $(y=141 \mathrm{~cm})$ above the head $\left(a: 18^{\circ} \mathrm{C} ; b: 24^{\circ} \mathrm{C} ; \mathrm{c}: 30^{\circ} \mathrm{C}\right)$ and vertically above the head $\left(\mathrm{d}: 18^{\circ} \mathrm{C}\right.$; e: $24^{\circ} \mathrm{C} ; \mathrm{f:} 30^{\circ} \mathrm{C}$ ). The original PST measurements are presented as a point cloud. The interpolated values-averaged in terms of time and space-are shown as a curve (PST avg). The air velocity measured by the anemometers is plotted including the standard deviation using error bars

the thermal boundary layer.

Figure 11 shows the temperature profile of the plume as measured by thermistors along a horizontal line above the head $(y=141 \mathrm{~cm}$, see also Figure 9) at different room temperatures. As with the IR measurements in the previously shown pictures, the air temperature directly above the head is the highest and decreases with increasing distance from the center of the manikin. The cooler the room temperature, the more pronounced is the plume. This is the result of the increased temperature gradient between the manikin and the air.

In order to compare IR and thermistor measurements, both were measured at several room temperatures and at different spatial positions, as shown in Figure 12. In Figures $12 \mathrm{a}-12 \mathrm{~b}$, the air temperature above the head is shown at different heights. Given the level of accuracy possible for each measurement method, the results of the thermistors and the thermography match well. 


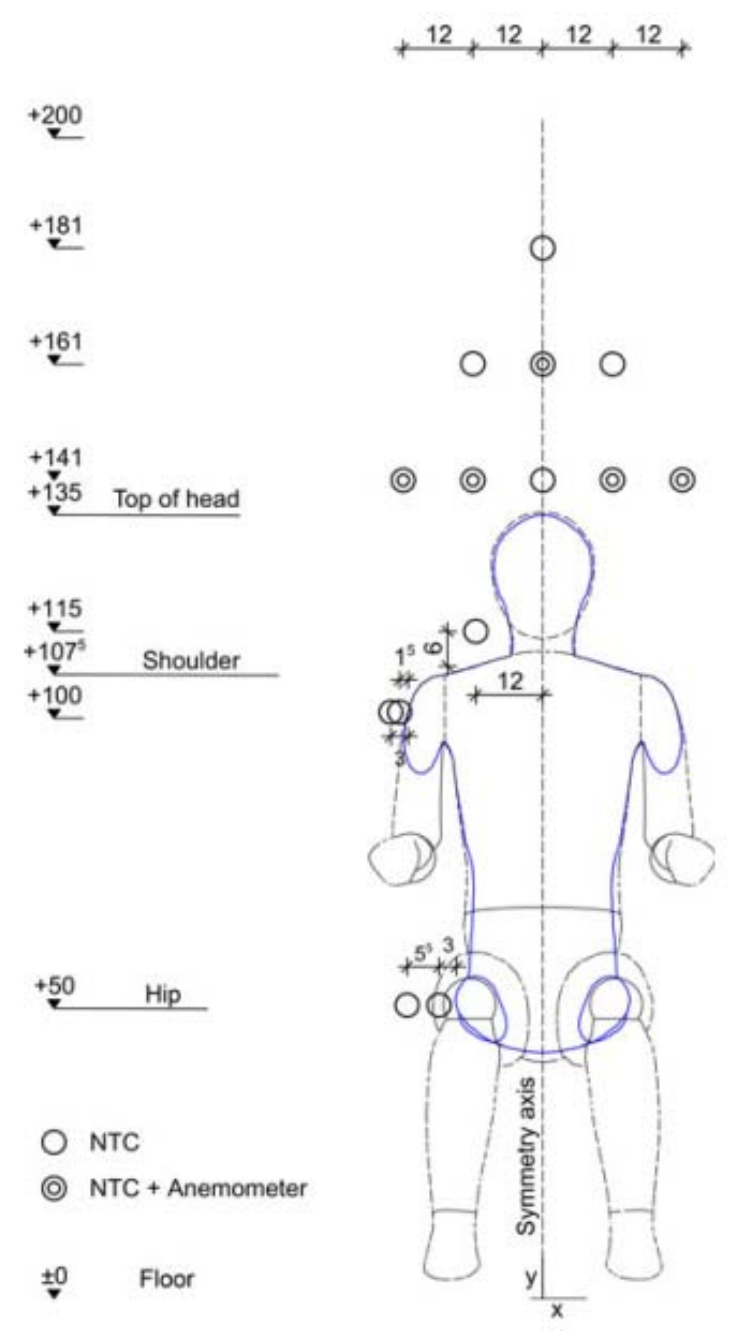

Fig. 9. Technical drawing of the temperature (NTC thermistors) and air velocity sensors (Anemometers)

There are slight deviations directly over the head, especially at low temperatures. The reason for this is the exposed nature of the location, which is associated with radiation exchange with the surrounding area: at colder room temperatures, the temperature difference between wall and auxiliary layer is larger, which means that radiation losses cool down the surface of the auxiliary layer. Furthermore, the radiative heat emitted by the walls is reflected by the auxiliary plane when the thermogram is taken. The radiation plays a more important role at higher temperature differences. In addition, the standard deviation of the measured values correlates with the temperature differences. The higher the temperature difference, the greater the variation in air temperature due to turbulence and instability of air flow.

In contrast, Figures $12 \mathrm{c}-12 \mathrm{~d}$ show the vertical temperature profile of the plume. Here, the first measuring point is the surface temperature of the manikin. The air temperature of the plume falls slowly but visibly with increasing height. In Figure 12e, the horizontal temperature profile of the micro-climate at the shoulders $(y=107 \mathrm{~cm})$ is shown. The air temperature decreases with increasing distance from the body until it reaches the value of the undisturbed air temperature. The same applies for the temperature profile at the hips $(y=50 \mathrm{~cm})$ in Figure 12f. However, this point seems rather inappropriate for thermography because the convection is influenced by the horizontal plane (see also Figure 4). In addition, this point on the plane exchanges radiation with other parts of the body (torso, thigh, and arm). This has an influence on both the real as well as on the measured temperature due to the reflection and absorption of radiation. Therefore, there are slight discrepancies in the measured air temperature between thermography and thermistors.

\subsection{Heat transfer coefficients}

As the thermal manikin is not able to simulate evaporative heat loss, our measurements only record sensible heat loss. Therefore, the total heat release of the thermal manikin (Q) consists of radiative plus convective heat losses, which can be calculated as

$$
Q=h_{r}\left(\theta_{\text {skin }}-\theta_{r}\right)+h_{c}\left(\theta_{\text {skin }}-\theta_{a}\right)
$$

The heat release $Q$, the skin temperature $\theta_{\text {skin, }}$ the radiative temperature $\theta_{\mathrm{r}}$ and the air temperature $\theta_{\mathrm{a}}$ are determined by our measurements, while the convective heat transfer coefficient $h_{c}$ and the radiative counterpart $h_{r}$ are not measured directly. Presumably, each body part has a different heat transfer coefficient due to its unique position. On the one hand, the position has an influence on the radiation exchange with the environment. On the other hand, convective heat release is influenced by the different characteristics of the micro-climate - its thickness, air temperature, air velocity and turbulence.

The following rearranged equation allows us to calculate the convective heat transfer coefficient:

$h_{c}=\frac{Q-h_{r}\left(\theta_{\text {skin }}-\theta_{r}\right)}{\left(\theta_{\text {skin }}-\theta_{a}\right)}$

The radiative heat transfer coefficient needed in equation (4) can be determined by (ASHRAE, 2005):

$h_{r}=4 \varepsilon \sigma \frac{A_{r}}{A_{D}}\left(273.2+\frac{\theta_{\text {skin }}+\theta_{r}}{2}\right)^{3}$. 


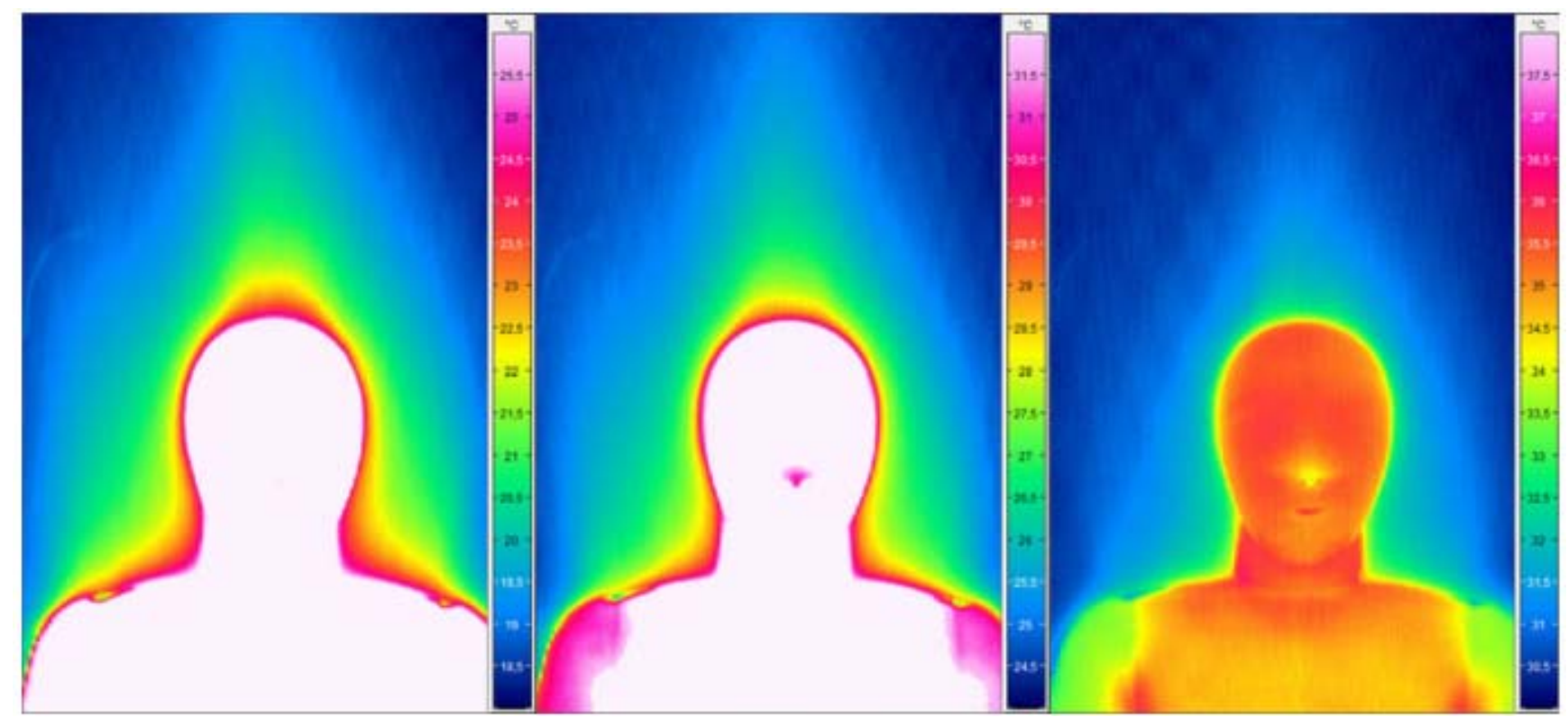

Fig. 10. Thermography of the work plane (left: $\theta=18^{\circ} \mathrm{C}$, center: $\theta=24^{\circ} \mathrm{C}$, right: $\theta=30^{\circ} \mathrm{C}$ ) shows the influence of the room temperature on the thermal plume

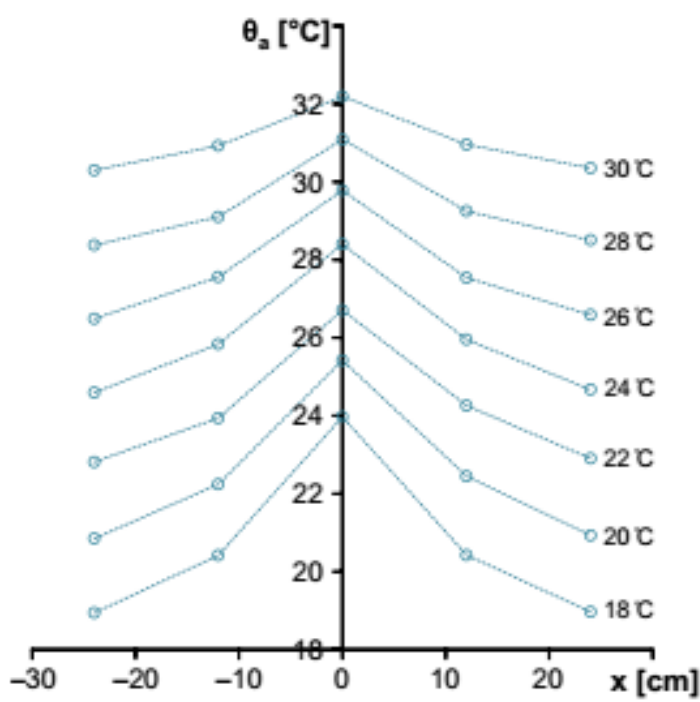

Fig. 11. Air temperature at different room temperatures, as measured by NTC thermistors. The cooler the room temperature, the more pronounced is the plume due to the increased temperature gradient between the manikin and the air

This simplified equation uses the emissivity $(\varepsilon=0.95)$, the Stefan-Boltzmann constant $\left(\sigma=5.67 \cdot 10^{8} \mathrm{~W} /\left(\mathrm{m}^{2} \mathrm{~K}^{4}\right)\right)$, the effective radiation area of the body $\mathrm{A}_{\mathrm{r}}$ and the DuBois surface area of the skin $A_{D}$. As these equations are general, they can be applied for the whole body as well as for single body parts. In this study, we used the effective radiation area factors $A_{r} / A_{D}$ provided by Oguro et al. (2002) for all body segments. Hence, the radiative heat transfer coefficient $h_{r}$ was calculated for every single body segment based on its boundary conditions.

Figure 13 shows the calculated radiative heat transfer coefficient based on equation (5). Due to differences in terms of skin temperatures as well as in terms of the effective radiation area factor, the radiant heat transfer of everybody segment is different. As expected, the coefficient increases slightly with increasing radiant and skin temperatures.

The convective heat transfer coefficients show the opposite tendency, as they fall with increasing temperatures. Additionally, there is a large variation between the segments: while fully exposed segments such as the foot or hand show quite high coefficients, relatively unexposed segments, such as the pelvis, have lower ones. At $30^{\circ} \mathrm{C}$, for example, the lowest and the highest coefficients vary by a factor of 3 .

\section{Conclusions}

The human body is surrounded by a micro-climate which results from heat release. It consists of a boundary layer and an ascending plume which both differ greatly in temperature and air velocity from the indoor climate surrounding the body. However, the properties of this microclimate are highly dependent on boundary conditions and the particular body segment in question. In this study, a series of measurements was carried out in a climate chamber equipped with a thermal manikin. The surface temperature of the latter was based on simulations using the UCBerkeley Thermal Comfort Model. For this reason, this approach is more complex, but might be also more precise than using fixed temperature values for temperature difference as provided by de Dear et al. (1997) and Sorensen and Voigt (2003). The micro-climate of the human body was investigated by combining conventional measurement methods (anemometry, thermistors) and more innovative techniques such as thermography and Particle Streak Tracking. 

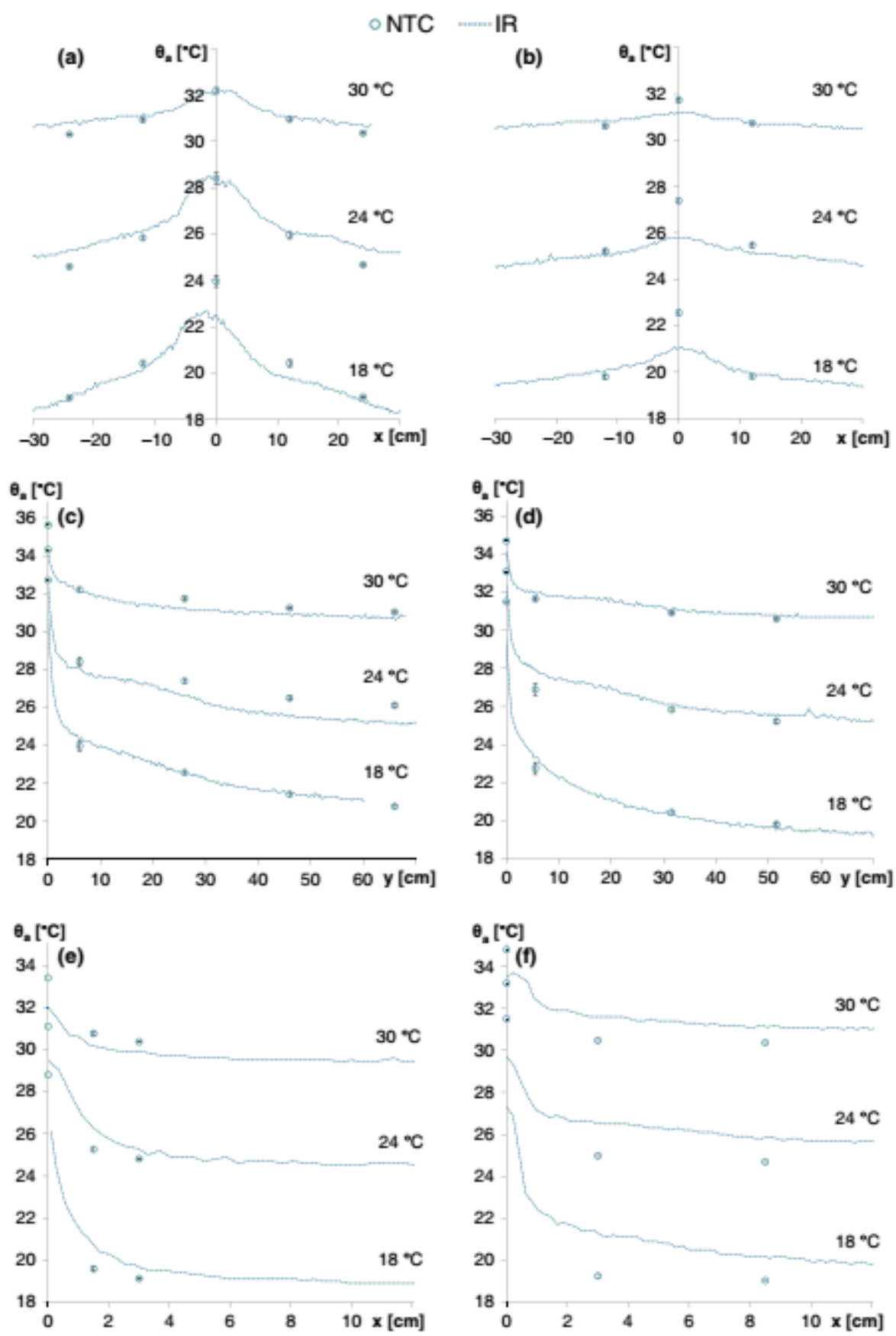

Fig. 12. Air temperature horizontally above the head ( $a: y=141 \mathrm{~cm} ; b: y=161 \mathrm{~cm}$ ); vertically above the head (c) and shoulder (d); horizontally at the shoulder (e) and hips (f).

Although making various simplifications was unavoidable (e.g. breathing), the measurement results are generally comparable to those with real humans from Craven and Settles (2006). Finally, the conclusions can be summarized as follows:

- Due to the convective heat release, the microclimate features temperatures in between room air temperature and surface temperature of the human body. This temperature gradient is responsible for an upward flow of air around the human body. The thickest part and hottest temperatures are to be found near the head, which is due to the changing geometry at the shoulders.

- $\quad$ The upward flow of air results in an ascending plume above the head, approximately a shoulder's width wide, but narrowing with increasing height.

- Skin temperature decreases with falling air temperature. However, because the skin temperature decreases more slowly, the temperature difference between skin and room air temperature increases. 

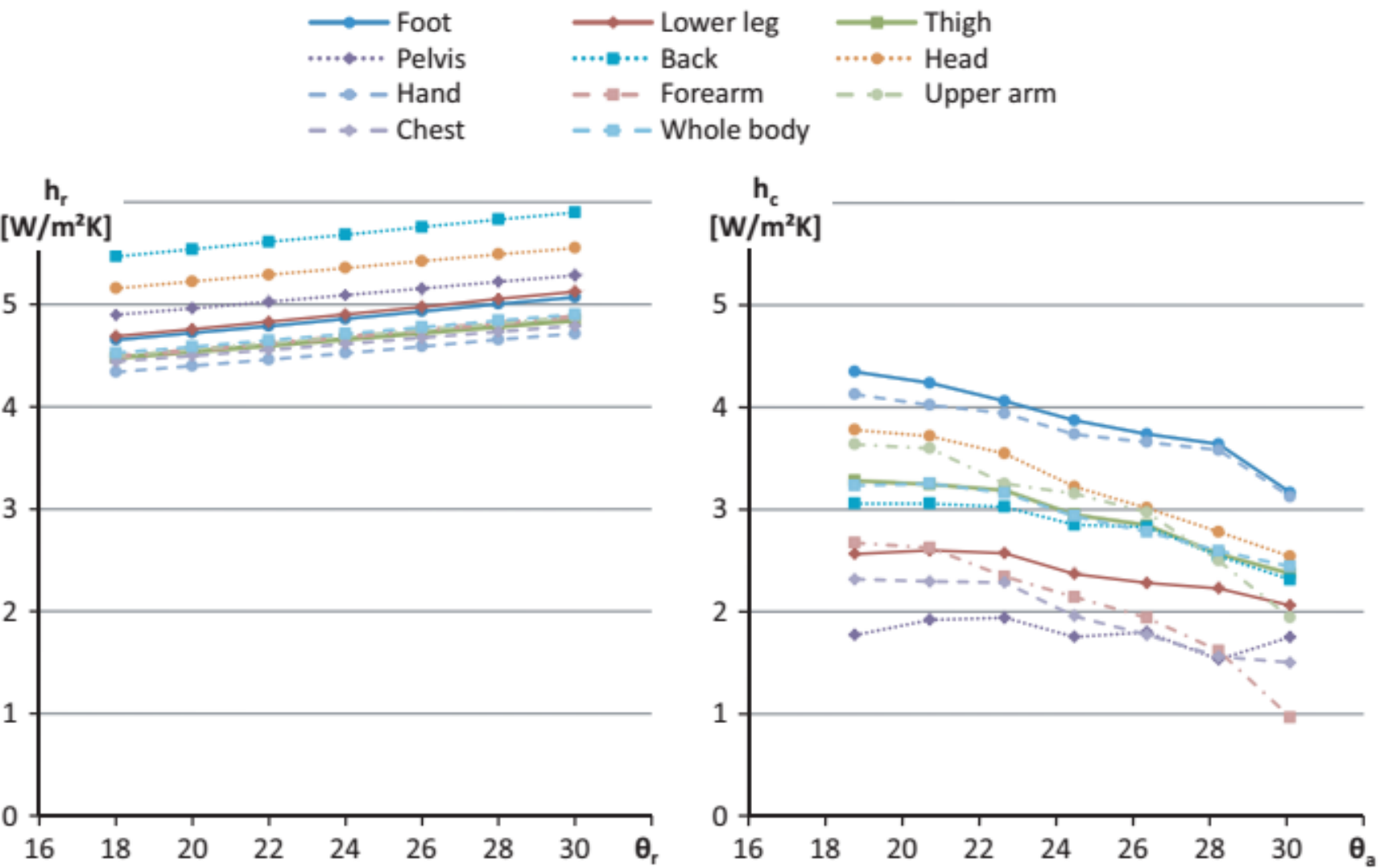

Fig. 13. Radiant heat transfer coefficients (left) increase slightly with increasing radiant and skin temperatures. Convective heat transfer coefficients (right) show a large variation between the segments and fall with increasing temperatures.

- The lower the air temperature, the greater the temperature difference between human surface and air. The higher the temperature gradient, the higher the air velocity. Additionally, there is a weak correlation between the air velocity and the turbulence of the flow.

- Comparing all body segments, the microclimate can strongly vary in thickness and shape, air velocity, air temperature and turbulence.

- This results in large differences between the body segments in terms of their convective heat transfer coefficient. Additionally, convective heat transfer coefficients strongly decrease with increasing room temperature.

- By contrast, radiative heat transfer coefficients increase with increasing room temperature and show only minor differences between body segments.

- The use of thermography and PST proved suitable for the measurement and visualization of the micro-climate.

- When applying PST, general knowledge of the air flow is important, for example in order to select an appropriate algorithm for temporal and spatial averaging of the measurement results. Monitoring with conventional sensors (e.g. anemometer) is recommended.

- Thermography is influenced by the radiation exchange with the surrounding surfaces which can influence the measurement results under unfavorable conditions. The control with conventional sensors (e.g. thermistors) proved necessary.

- The instability and turbulence of the flow necessitates a time averaging of the measurements results in order to make the results comparable with RANS-based CFD simulations.

The findings of this paper generate a better understanding of the human body's micro-climate. The dependency of its characteristics from the boundary conditions and the particular body segment show the value of undertaking such a detailed investigation. This knowledge is useful in fields dealing with thermal comfort, HVAC, indoor air quality and the spread of airborne diseases. The measurements can also be used for the validation of CFD simulations.

\section{Acknowledgement}

This paper forms part of our work in the research project "Methoden und Baustoffe zur nutzerorientierten 
Bausanierung", which was funded by the German Federal Ministry for Education and Research (BMBF) and administrated by Projektträger Jülich. Additionally we highly appreciate the cooperation with the Center for the Built Environment, UC Berkeley.

\section{References}

Ashrae (2005) ASHRAE Handbook - Fundamentals, SIEdition, Atlanta, American Society of Heating, Refrigerating and Air-Conditioning.

Cehlin, M., Moshfegh, B. and Sandberg, M. (2002) "Measurements of air temperatures close to a low-velocity diffuser in displacement ventilation using an infrared camera", Energy and Buildings, 34, 687-698.

Craven, B.A. and Settles, G.S. (2006) "A computational and experimental investigation of the human thermal plume", Journal of Fluids Engineering, 128, 1251-1258.

Dahms, A., Rank, R. and Müller, D. (2007) "Enhanced Particle Streak Tracking system (PST) for two dimensional airflow pattern measurements in large planes". In: Proceedings of Roomvent.

De Dear, R.J., Arens, E., Hui, Z. and Oguro, M. (1997) "Convective and radiative heat transfer coefficients for individual human body segments", International Journal of Biometeorology, 40, 141-156.

Deevy, M., Sinai, Y., Everitt, P., Voigt, L. and Gobeau, N. (2008) "Modelling the effect of an occupant on displacement ventilation with computational fluid dynamics", Energy and Buildings, 40, 255-264.

Dygert, K.R., Dang, T.Q., Russo, J.S. and Khalifa, H.E. (2009) "Modeling of the human body to study the personal micro environment", ASHRAE Transactions, 115, 407-420.

Gao, N. and Niu, J. (2004) "CFD study on microenvironment around human body and personalized ventilation", Building and Environment, 39, 795-805.

Huizenga, C., Zhang, H. and Arens, E. (2001) "A model of human physiology and comfort for assessing complex thermal environments", Building and Environment, 36, 691699.

Licina, D., Tham, K.W., Pantelic, J. and Sekhar, S.C. (2013) "Experimental characterization of the human convective boundary layer in a calm indoor environment". In: Proceedings of ASHRAE IAQ 2013, pp. 428-435.

Melikov, A. (2004) "Breathing thermal manikins for indoor environment: important characteristics and requirements", European Journal of Applied Physiology, 92, 710-713.

Müller, D. (2000) Optische Erfassung und numerische Berechnung von zwei- und dreidimensionalen Geschwindkeitsfeldern mit niedrigen turbulenten Reynoldszahlen. PhD thesis, RWTH Aachen.
Murakami, S. (2002) "CFD study on the micro-climate around the human body with inhalation and exhalation". In: Proceedings of Roomvent, Vol. 1, pp. 23-35.

Murakami, S. (2004) "Analysis and design of microclimate around the human body with respiration by CFD", Indoor Air, 14 144-156.

Murakami, S., Kato, S. and Zeng, J. (1997) "Flow and temperature fields around human body with various room air distribution. CFD study on computational thermal manikin Part 1", ASHRAE Transactions, 103, 3-15.

Murakami, S., Zeng, J. and Hayashi, T. (1999) "CFD analysis of wind environment around a human body", Journal of Wind Engineering and Industrial Aerodynamics, 83, 393408.

Nilsson, H., Brohus, H. and Nielsen, P.V. (2007) Benchmark test for a computer simulated person - Manikin heat loss for thermal comfort evaluation, www.cfdbenchmarks.com, Last access: 20.08.2012.

Oguro, M., Arens, E., De Dear, R., Zhang, H. and Katayama, T. (2002) "Convective heat transfer coefficients and clothing insulations for parts of the clothed human body under calm conditions", Journal of Architectural Planning and Environmental Engineering, 31-39.

Sevilgen, G. and Kilic, M. (2011) "Numerical analysis of air flow, heat transfer, moisture transport and thermal comfort in a room heated by two-panel radiators", Energy and Buildings, 43, 137-146.

Sorensen, D.N. and Voigt, L.K. (2003) "Modelling flow and heat transfer around a seated body by computational fluid dynamics", Building and Environment, 38, 753-762.

Tanabe, S., Kobayashi, K., Nakano, J., Ozeki, Y. and Konishi, M. (2002) "Evaluation of thermal comfort using combined multi-node thermoregulation (65MN) and radiation models and computational fluid dynamics (CFD)", Energy and Buildings, 34, 637-646.

Tang, J.W., Nicolle, A.D.G., Pantelic, J., Jiang, M., Sekhr, C., Cheong, D.K.W. and Tham, K.W. (2011) "Qualitative realtime schlieren and shadowgraph imaging of human exhaled airflows: An aid to aerosol infection control", PLoS ONE, 6.

Voelker, C., Hoffmann, S., Kornadt, O., Arens, E., Zhang, H. and Huizenga, C. (2009) "Heat and moisture transfer through clothing". In: Proceedings of Building Simulation, pp. 1360-1366.

Voelker, C. and Kornadt, O. (2010) "Simulation and measurement of thermal comfort [Simulation und Messung der thermischen Behaglichkeit]", Bauphysik, 32, 365-372.

Voelker, C. and Kornadt, O. (2012) "Automated coupling of CFD and human thermoregulation modelling considering local climatic parameters". In: Proceedings of 5th IBPC, pp. 945-951. 